\title{
Application of an innovative, autonomous, creative teaching modality through service-learning in a community-health nursing course
}

\author{
Susan G. Williams, Suzanne Bihan \\ College of Nursing, University of South Alabama, Mobile, AL, United States
}

Correspondence: Susan G. Williams. Address: College of Nursing, University of South Alabama, Mobile, AL, United States. Email: sgwilliams@usouthal.edu.

Received: June 28, 2012

DOI : $10.5430 /$ jnep.v3n5p116
Accepted: October 10, $2012 \quad$ Online Published: December 17, 2012

URL: http://dx.doi.org/10.5430/jnep.v3n5p116

\section{Abstract}

Nursing faculty continue to find themselves challenged to meet student needs by the increasing student enrollment numbers and increasing faculty workloads without simultaneously increasing resources. The responsibility to meet student needs rests on the nursing faculty. It is therefore increasingly important that nursing faculty implement teaching modalities to meet student and patient needs. This article demonstrates faculty's use of service-learning as an effective, innovative teaching modality to meet increasing student, patient, and community needs without additional resources. The authors seek to differentiate between service learning and contracted clinical experiences in order to enable nurse educators to use service learning as a teaching modality. The authors describe the process of using service learning with nursing process in this course. Nursing assessment is built into the project as a "windshield survey". A literature review was conducted seeking to understand other uses of service learning in education and validate the authors' experiences. This three-credit hour lecture and one credit hour clinical course has yielded unique and interesting service learning projects that positively impact their communities. The students work with cohorts of all races, ethnicities and cultures throughout the lifespan. Service-learning opportunities assist in the availability and accessibility of health care to safety net facilities and vulnerable populations who may not otherwise receive health care screening or treatment. Faculty in nursing and other health disciplines will likely appreciate the innovation, creativity, and autonomy afforded this modality of outreach.

\section{Key words}

Nursing, Service-learning, Education, Community health, Clinical experience

\section{Introduction}

The lack of qualified nursing faculty and its effect on the nursing shortage has been well documented ${ }^{[1]}$. When addressing the nursing shortage, “The AACN 2006-2007 Enrollment and Graduation Survey found 71\% of respondents cited the nursing faculty shortage as the primary reason for restricting student enrollment” ${ }^{[2]}$. Compounding the nursing shortage Cashman reports:

"Increasingly, health care facilities worldwide, particularly those that comprise the safety-net, are finding themselves understaffed and challenged to meet patients' needs. Identifying additional sources of support and 
resources is critical for facilities to be able to sustain current and develop new initiatives to improve patients' health" ${ }^{[3]}$.

Community health nursing continues to be an area of mystery and low priority to nursing students and nurses who are not familiar with this specialized area of nursing. Student nurses quickly learn that community health nursing is about people, individuals, and aggregate groups or populations living in close proximity that have common agencies and institutions ${ }^{[4]}$.

Throughout the community health nursing theory course, students explore the various roles of a community health nurse in areas such as public health, epidemiology, disaster management, vulnerable populations, rural and migrant health, homelessness, teen pregnancy, infectious disease and violence and abuse. Hallmarks of a community health course include learning and investigating issues related to affordable care, health policy and law, social justice, environmental and economic trends, advocacy and ethics, disaster management, surveillance and outbreak investigation and family health across the lifespan ${ }^{[4]}$. There are many different types of nursing in community settings. For example: parish nurses, home health nurses, hospice nurses, school nurses, case managers, and occupational health nurses ${ }^{[4]}$. Students in this course are at the senior level and will be finishing the nursing program in less than 6 months. Many times these students have already chosen their path in nursing and are interested in intensive care nursing, emergency room nursing, obstetrics and gynecology nursing, pediatric nursing, psychiatric nursing or nursing of the elderly. The students may not have thought about other opportunities that lie outside of the hospital that can be challenging and exciting as well as a tremendous help to their home community.

The goal of the practice of community health nursing is to protect, promote, preserve, and maintain the health of the population within a given community ${ }^{[4]}$. The service-learning projects described in this paper ultimately met the identified various needs of nursing faculty, students, and the community. Those facilities involved as the community's safety-net providers (health personnel offering services to uninsured and underinsured ${ }^{[4]}$ ) were able to receive services and innovations from the student nurses that otherwise would not have been available to them.

The article addresses how this course has increased nursing student's ability, compassion and enthusiasm for serving their local community with their nursing knowledge and skills. The student's assessment and awareness of needs in the community led to the development of service-learning projects that were meaningful as well as providing needed, effective services to a selected community. The authors distinguish service-learning from community health nursing clinical experiences. Table 1 addresses the outcomes achieved by more than 200 students over two semesters.

Table 1. Projects completed in last year by four different classes (2 Traditional BSN/2 Accelerated BSN)

\begin{tabular}{llll}
\hline $\begin{array}{l}\text { Community } \\
\text { Location }\end{array}$ & Population & $\begin{array}{l}\text { No. Nursing } \\
\text { Students }\end{array}$ & Topic \\
\hline AL & School Children (Elementary) & 3 & Dental Hygiene \\
AL & Preschool Children & 4 & Hygiene, Nutrition \& Exercise \\
AL & Assisted Living Community & 4 & Vital Signs \& Wellness \\
AL & Assisted Living Facility & 4 & Vital Signs \& Exercise \\
AL & Indigent care clinic & 3 & Medication \& Nutrition Teaching \\
AL & Senior Day Center Adults & 4 & Vital Signs \& Medication Teaching \\
AL & Walkers - General Population at Pier & 4 & Vital Signs \& Medication Teaching \\
AL & After School Children & 4 & Nutrition \&Exercise \\
AL & Nursing Home Elderly & 3 & Community Safety \\
AL & Homeless Population & 4 & Nutrition \\
AL & Adolescents - 8 ${ }^{\text {th }}$ grade & 20 & Health Career fair \\
AL & Indigent Care clinic & 8 & Vital signs \& foot care \\
\hline
\end{tabular}

(Table 1 continued on page 118) 
Table 1. (continued)

\begin{tabular}{|c|c|c|c|}
\hline $\begin{array}{l}\text { Community } \\
\text { Location }\end{array}$ & Population & $\begin{array}{l}\text { No. Nursing } \\
\text { Students }\end{array}$ & Topic \\
\hline $\mathrm{AL}$ & School Children (Middle school) & 4 & CPR \\
\hline AL & School Children (Elementary) & 4 & Nutrition\&obesity in children \\
\hline AL & Homeless Individuals & 20 & Nutrition \& Hygiene \\
\hline AL & Nursing Home Elderly & 4 & Hygiene, Self Esteem\& ADL's \\
\hline AL & School Children (Elementary) & 4 & Hand washing \&Infection Control \\
\hline AL & Alzheimer’s Facility & 4 & Fall Risk\&Nutrition \\
\hline AL & School Children (Elementary) & 4 & Hand washing \&Infection control \\
\hline AL & School Children (Elementary) & 4 & Hand washing \\
\hline AL & Senior Day Center Adults & 4 & Nutrition \&Hydration \\
\hline AL & College Students (sorority) & 4 & Campus Safety \\
\hline AL & College Students (Sorority) & 4 & Breast Cancer Awareness \\
\hline AL & School Children (Elementary) & 4 & Dental Hygiene \\
\hline AL & Children's group home & 4 & Exercise \\
\hline AL & School Children (Elementary) & 3 & Hand washing\&Infection Control \\
\hline AL & Senior Adults & 34 & Health Fair \& First Aid booth \\
\hline AL & After School Children & 4 & Helmet Safety \\
\hline AL & Low income population & 4 & Vital Signs\&Wellness \\
\hline AL & Assisted Living Facility & 4 & Hydration \& Fall Safety \\
\hline AL & School Children ( Elementary) & 4 & Obesity Prevention \\
\hline AL & Elderly Residential Living & 4 & Nutrition \&Hydration \\
\hline AL & School Children (Elementary) & 4 & Exercise \& Nutrition \\
\hline AL & Retirement Center & 4 & Nutrition \& Hydration \\
\hline AL & Preschool Children (Deaf and Blind) & 4 & Dental Hygiene \\
\hline AL & After School Children & 4 & Helmet Safety\&Nutrition \\
\hline AL & School Children (Middle School) & 4 & Exercise \&Nutrition \\
\hline AL & School Children (Elementary) & 4 & Dental Hygiene \\
\hline AL & School Children ( Elementary) & 4 & Traffic Safety \\
\hline AL & School Children (Elementary) & 4 & Nutrition \\
\hline $\mathrm{AL}$ & Police Department & 4 & Vital Signs \&Wellness \\
\hline AL & Hispanic Community & 4 & Hypertension Screening \\
\hline AL & School Children & 4 & Nutrition \\
\hline AL & School Children & 8 & Hand washing\&Infection control \\
\hline AL & Fire Department & 4 & Vital signs, blood glucose, \&wellness \\
\hline AL & After School Children & 4 & Exercise \& Nutrition \\
\hline $\mathrm{AL}$ & School Children (Elementary) & 4 & Hygiene \\
\hline FL & School Children (Intermediate ) & 4 & Nutrition \\
\hline FL & Beach goers & 8 & $\begin{array}{l}\text { Sun screen, alcohol \& hydration } \\
\text { advisory }\end{array}$ \\
\hline FL & School Children & 4 & Exercise \& Diet \\
\hline MS & School Children (Elementary) & 4 & Exercise \& Diet \\
\hline MS & School Children (Elementary) & 3 & Hand washing\&Infection Control \\
\hline MS & School Children (Elementary) & 4 & Hand washing\&Infection Control \\
\hline
\end{tabular}




\section{Review of literature}

Literature related to service and learning can be found as far back as 1903, when the cooperative education movement was founded and expanded with a growing focus on the connection between service and learning ${ }^{[5]}$. The review of literature was conducted using the Cumulative Index to Nursing \& Allied Health Literature, (CINAHL) database. A search was conducted using the key words, nursing, service-learning, public health and education. The search was limited to peer reviewed, abstract available, and full text articles published from January 2004 through May 2012. Two hundred and fifty eight journal articles were available. The author then reviewed abstracts, and the number was reduced to 25 journal articles. Most definitions of service-learning were found to be similar to the definition used by the author, "Servicelearning is a teaching and learning strategy that integrates meaningful community service with instruction and reflection to enrich the learning experience, teach civic responsibility, and strengthen communities" ${ }^{\text {"[6] }}$. Furthermore, a service-learning project was defined as "A collegial relationship between the academic setting and the community setting, which establishes a need for an identified activity that can be provided by students” ${ }^{[7]}$.

Service-learning is an educational movement across the United States used by many disciplines to help students think critically and apply new knowledge learned in the classroom to real - life situations ${ }^{[8]}$. The involvement of students in service-learning helps to build character, promote active engagement in their communities, and promote collaboration with classmates as well as community agencies and populations of vulnerable people. Cashman et al. reported,

"At a time of shrinking resources, individuals and communities worldwide often find themselves facing increasingly complicated health needs. The worsening mismatch of resources and needs has prompted many institutions to develop or expand partnerships, with the aim of realizing mutual benefit” ${ }^{\text {[3] }}$.

By the time a nursing student is at the senior level, he or she has learned many technical skills such as vital signs, nursing health assessment, medication administration, and use of the nursing process. These students also have extensive knowledge of pharmacology and pathophysiology ${ }^{[9]}$. These skills are useful in community settings of all types. Vulnerable populations who may benefit from service-learning, even for short periods include the elderly, homeless individuals and families, children, and students. Other populations include pregnant women, drug addicted individuals, HIV positive individuals, or individuals working in environments that are subject to transmission illnesses such as the flu.

Students, faculty, the university, and the community benefit from service-learning in different ways. Students often feel more engaged and motivated to participate in projects that they have designed and that are located in their specific community. These experiences can build student self-esteem, provide opportunities to explore potential career options, develop civic responsibility, promote future volunteerism, and strengthen personal and social skills, and leadership abilities ${ }^{[10]}$. This experience also strengthens the student's ability to practice cultural sensitivity and competency across the lifespan.

For a faculty member, service-learning can promote interdisciplinary collaboration, bring the curriculum to life by involving students in action-oriented projects, and provide professional development and possible funding opportunities. The university benefits from service-learning because of the outreach to the community, public recognition of students assisting in community agencies, recruitment of potential students, retention of current students, and contribution to the over-all mission of the university regarding to service to the community at large ${ }^{[10]}$. Community members most likely receive the greatest benefit of service-learning through meeting of the agency's or population's needs. Students and faculty provide expertise that might not otherwise be available, while the population becomes more knowledgeable regarding topics or issues ${ }^{[10]}$. 


\section{Clinical nursing practical experience}

Generally a student is assigned to a clinical nursing practical experience in an agency under a contract to the university. Nursing faculty supervises the students and guides their experience in keeping with the following guidelines of the American Association of Colleges of Nursing (1999).

"Clinical site-based learning provides a variety of options for students and faculty working within a single health care delivery system or across several systems:

- Within a single health care delivery system, students learn the operation and services of that setting and deliver and manage nursing care to patients requiring different services within that setting/system.

- In non-institutional settings where there is a greater emphasis on prevention or population focused care, clinical site-based learning may be obtained in a variety of community-based settings as well as in acute care settings.

- Community-based settings may provide excellent opportunities for students to develop not only individual patient care skills but also population/group care skills and leadership/management skills. Expanded practice environments include homes, clinics, community centers and shelters, schools, industrial settings, rehabilitation centers, and nursing homes" ${ }^{[1]}$.

The nursing students have been exposed to and used nursing process in previous clinical courses such as Adult I, Pediatrics/Obstetrics, and Psychiatric Mental-Health Nursing. Throughout these clinical experiences, the students have been under the direct supervision of an instructor through the contracted relationship with the clinical partner. Community Health Nursing is the first autonomous, self-chosen, self-directed experience of the student's nursing practice. The nursing process guides the students through their trajectory within their chosen community sites. All phases of the nursing process are practiced in the community health project.

\subsection{Differences between service-learning and a community clinical experience}

Outcome goals are very similar in that both service-learning and a community clinical experience provide opportunities for student nurses to apply knowledge of community health nursing to a local area. Usually, the clinical experience involves a period of time (over 4 weeks) with repeated visits to a particular agency and is set up by the community health nursing faculty in particular setting such as schools, senior centers, public health and home health or hospice care ${ }^{\text {[11] }}$. According to the Essentials of Baccalaureate Nursing Education for Entry Level Community/Public Health Nursing, in a community health clinical experience it is important for students to gather comprehensive information related to the health of a community or population. This assessment is considered a core health function that leads to recognition of "assets, needs, beliefs, practices, resources and environmental factors of a population being studied" ${ }^{[12]}$. The experience allows the novice student nurse to participate in delivering services to the public.

The service-learning experience involves a team project where students have more autonomy and choice not only in the community they assess, but in the type of project implemented, the resources interviewed, and the preceptor selected. The faculty member is involved in both a community health clinical experience and service-learning. It is important that the faculty member ensures that either experience is meaningful and in a learning environment ${ }^{[1]]}$. A similar course in San Antonio Texas was conducted with graduate nursing students. These students worked together to make a city wide change related to health protection and promotion by generating public interest in the lack of fluoride in the city water supply. This led to a vote to make changes that will continue to improve the health of residents in San Antonio for years to come ${ }^{[13]}$. 
Service-learning and the community clinical experience both use a process to accomplish goals. For service-learning, the steps are Investigation, Planning, Action, Reflection, Demonstration and Celebration ${ }^{[10]}$. Community clinical experience utilizes the nursing process steps of Assessment, Analysis, Planning, Implementation and Evaluation ${ }^{[11]}$. It may be difficult for students that have focused on individual acute care to switch to a population in a community setting. Therefore, with either service-learning or the community clinical experience, the faculty must rely on a preceptor in a community resource agency to act as a role model to the students as they expose them to services that are offered to the local community. Many times, the faculty must provide guidance for the preceptor as to how to incorporate the students in a learning process. This may ultimately lead to a strong professional bond with a resource agency where a relationship can continue to flourish ${ }^{[11]}$.

In a community clinical experience, students often complete reflective journals that provide evidence of educational and professional development ${ }^{[11]}$. Service-learning also includes reflection, but this is usually done in the classroom at the end of the semester and is shared with the class and teaching faculty. Students in this course must also include individual evaluations in their final paper discussing what each student contributed to the project, group dynamics process and satisfaction or lack of satisfaction in the project.

\subsection{Activity description}

The students conduct an assessment of their chosen community or a "Windshield Survey" ${ }^{[4]}$ and are allowed to work in groups of no more than four. Without assessment, the nurse has no accurate data to guide his or her practice. This project demonstrates the importance and role of assessment in effective nursing practice. The Windshield Survey involves a systematic approach wherein the nursing student identifies the community's needs, clarifies problems, and investigates the community's strengths and resources $^{[4]}$. The purpose of a Windshield Survey is to explore a particular community while thinking critically and identifying health problems seen while driving through the area.

The community/population can be as big or small as the student group wants it to be as long as there is a group of individuals living in close proximity who share a common environment ${ }^{[4]}$. As examples, a "community" might involve students living in the dorm on a university campus or a population of individuals living near the beach. As students assess their chosen population, they take notes on housing and zoning, open space, boundaries of the community, common areas, transportation, service centers, stores, street people, signs of decay, race, ethnicity, religion, and health risks ${ }^{[4]}$.

Issues of morbidity, mortality, census, politics, media, and available services are investigated through use of information at the United States Census Bureau and the Centers for Disease Control and Prevention. Students identify risk behaviors of the population as well as service deficits, reportable diseases, and environmental hazards specific to their chosen community. All of the above information is determined by interviewing informants in at least two resource agencies within the community. Furthermore, students investigate environmental issues on the Environmental Protection Agency (EPA) website or other internet sources that will provide information pertinent to the location of interest.

Once the student groups have selected a community/population and completed the Windshield Survey, students interview a staff member of the resource agency selected to ascertain what the agency sees as problems for community residents and how the student group might intervene with this problem. The resource person will ultimately be the group's "preceptor" if willing to supervise the students as they do their project within the community. For example, a group might chose to interview the staff at the local American Cancer Society (ACS) and find an issue related to failure to use proper skin protection among people who frequent the local beach. The person who may or may not be a nurse at the ACS will serve as the student group's preceptor (see Table 4) and help to guide the group in developing a service-learning project that might address and intervene with the identified problems of that particular population. In the case of the above example, a student group assimilated teaching materials, including written educational information about sunburn and skin damage, samples of sunscreen and bottles of water to persons visiting the beach on a particular weekend. The ACS provided the information, the students provided bottled water, and a local dermatology clinic provided sunscreen, creating a truly collaborative project within the community. 
Students utilize the total nursing process. Assessment is completed through the windshield survey, interviews and manual attainment of data. A problem is identified through collaboration with the interviewed resources and identified preceptor. The identified problem is then written in terms of two nursing diagnosis. Population, culture, developmental and solution appropriate interventions are selected and students carry out these interventions through educational, informational, or activity seminars. The instructor and preceptor are present for the intervention portion of the project and both assess and provide evaluation to the students in verbal and written format. The chosen populations are given the opportunity for anecdotal feedback and evaluation. Once the student project is completed, the students write a group paper using specific guidelines as depicted in Table $2 \& 3$. Part one (see Table 2) of the paper includes an assessment of the community, census data, environmental hazards, risk behaviors, and reported diseases and two community nursing diagnoses (e.g. "Risk for injury related to sunburn"). Part two (see Table 3) addresses the specifics involved in planning, implementing and evaluating the project. A description of the resource agency is included in this part of the paper along with information collected during the initial interview. Students must include a summary of an evidence-based article from a peer-reviewed journal that focuses on a problem or a community similar to the one chosen. The article must address a similar population, area, problem, and an intervention used to resolve the problem. Each individual student also writes a summary of the group work experience and discusses each member's contribution to the project.

Table 2. Windshield Community Project Assignment Grading Rubric Part 1

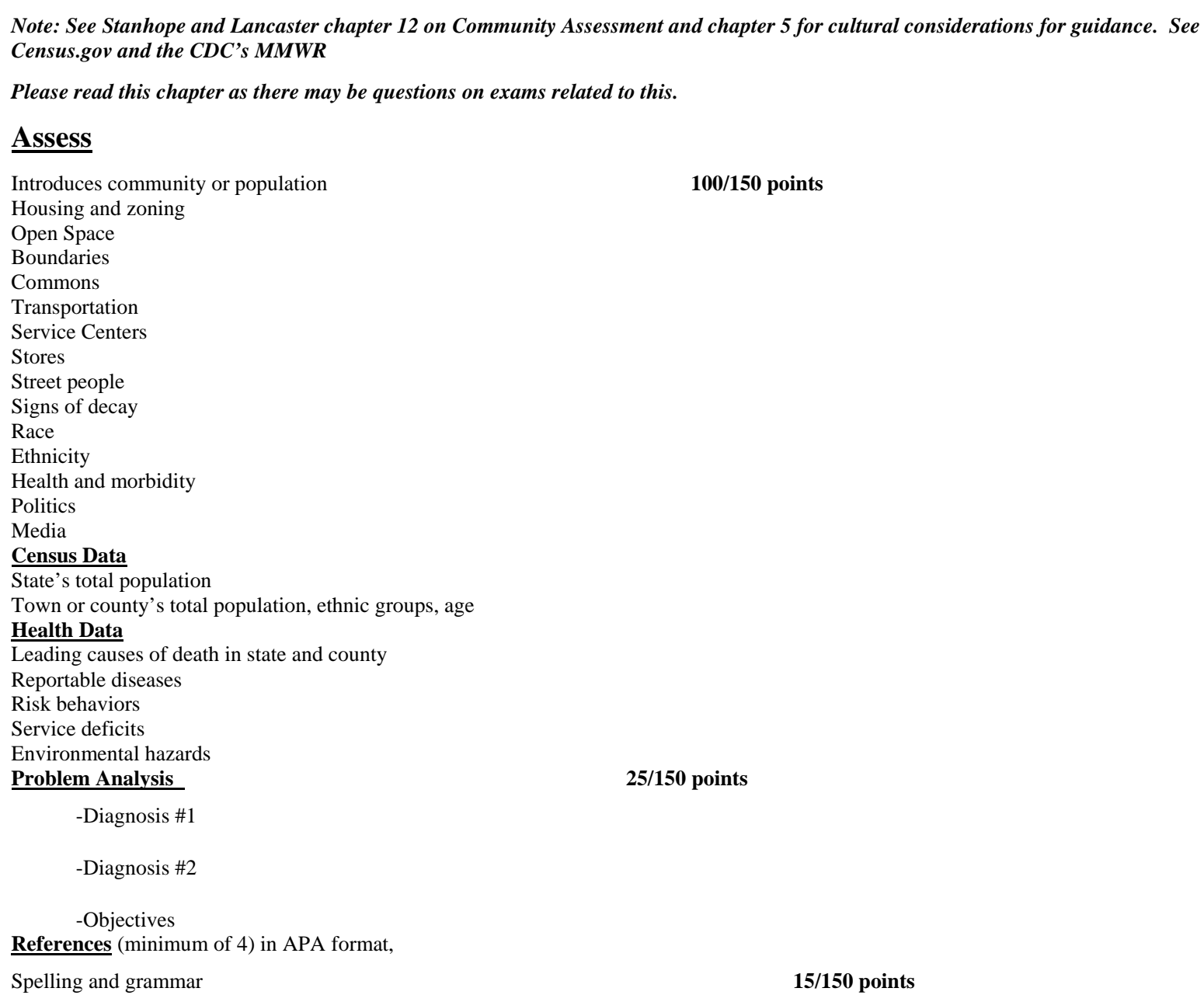

Total Points: 150 points 
Table 3. Implementation: Grading Rubric

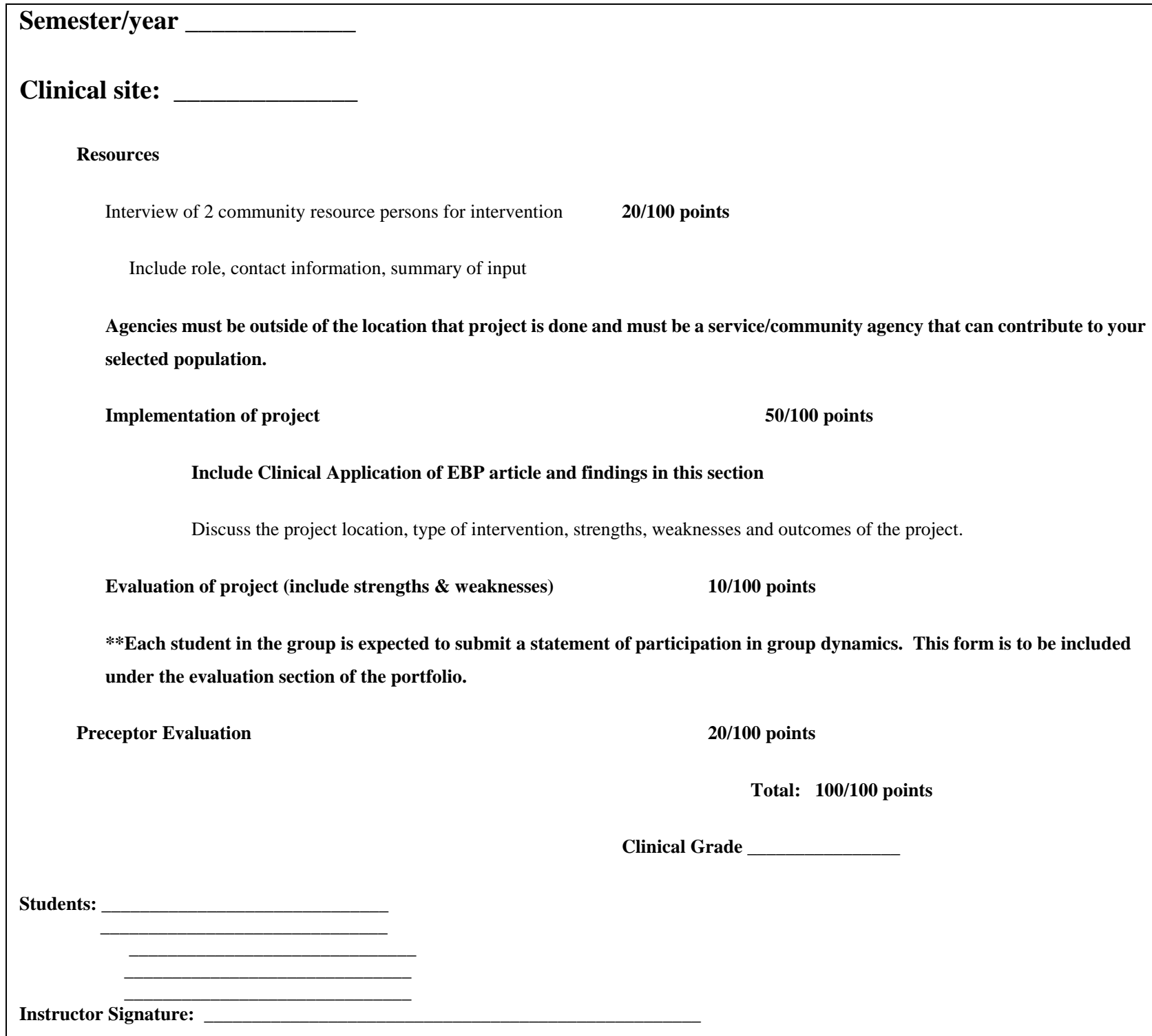

The groups generally work well together and divide the work evenly. The paper is the responsibility of the entire group, and all must participate in each process including reviewing the paper for errors in grammar, punctuation and APA format. Their "preceptor" from the resource agency is asked to sign a form (see Table 4) rating the students on a scale of 0-4 (with 4 being the highest rating). An assessment of the value of the project to the agency or community and additional comments may be added as the preceptor desires.

Students are asked to present their project to the classmates on the last day of class. The presentation includes the community that was selected, the resource agencies used, the population studied, and a description of the project that was developed, implemented and evaluated. The presentations involve informal discussions with the class. Some groups have developed Power Points presentations or video clips of the community that they studied, although this was not a requirement. The paper is submitted in a 3 ring binder and can include photos of the students doing their projects, maps of the community surveyed; or examples of educational materials used such as flyers, coloring pages, information sheets. This day is usually one of enthusiasm, pride, and accomplishment as the projects are presented. 
Table 4. Preceptor Evaluation

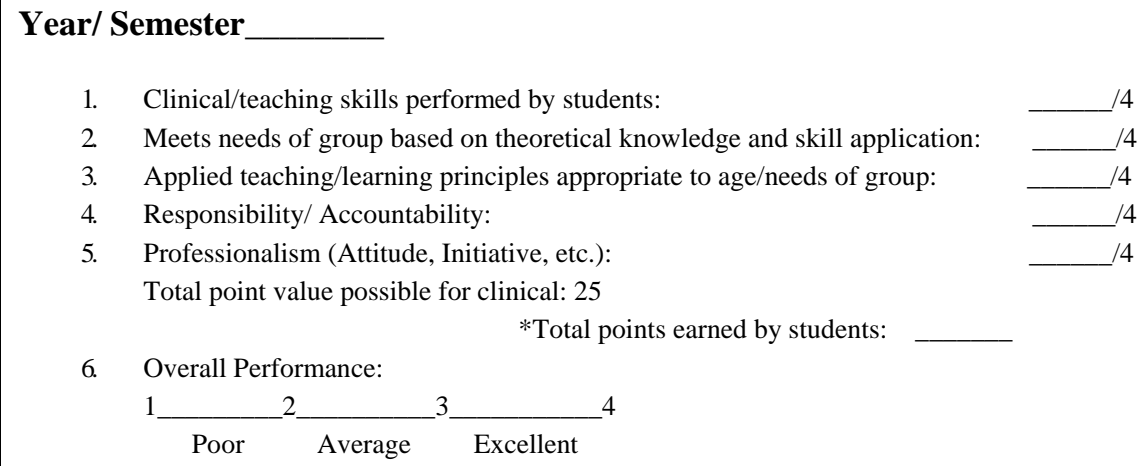

\subsection{Outcomes}

Student learning outcomes in clinical courses have consistently been difficult to assess objectively. Indeed this is true in community health where the focus or "client" presents as the chosen population versus one person or one family. Outcomes of the service-learning projects were evaluated through direct supervision by one of the course instructors, standardized preceptor evaluation tool (see Table 4), anecdotal notes from the resource agency and completed documentation of the student's "windshield project", assessment, nursing diagnosis, plan of care, interventions, and evaluation. Teamwork, use of principles learned in psychiatric mental health nursing, such as engagement, communication, motivational interviewing and use of research principles in terms of sampling a population are also evaluated by the instructor. Use of evidence based practice literature is required as a component of successful completion of this project. The student learning project allows the student nurse to put into practice the principles they may have learned regarding service work as a part of their profession. Wade and Hayes reported,

"Preceptored community experiences present challenges different from those of preceptored experiences in the acute care setting. Instead of focusing on psychomotor skills, faculty must address population-based skills and assess students' abilities to practice these skills. Faculty and preceptors' lack of knowledge to teach these skills further complicate the experiences, an issue indirectly related to faculty and nursing shortages. Although preceptors guide students, faculty are responsible for evaluating students in community preceptored experiences. The Association of Community Health Nursing Educators (ACHNE) Essentials of Baccalaureate Education (Essentials) offers opportunities for guiding and evaluating community health preceptored clinical experiences. Assignments and activities that reflect the ACHNE Essentials provide a firm foundation for the population focus of the course. This focus is validated through faculty visits to students in a variety of community settings. To plan successful community experiences and evaluate students, faculty must be knowledgeable about the population focus of community courses, apply this knowledge to students in a variety of settings, and ask challenging questions to assess student learning. To make a major paradigm shift from a focus on individual clients to the 
community as a client and use community partners to address common goals, students need to broaden their thinking beyond the acute care role" ${ }^{[12]}$.

The service-learning project allows students to gain an appreciation for the community and chosen population. Students were able to use the nursing process to conceptualize populations and groups of people that they may not have noticed before. Students claimed surprise at the disregard for and isolation of Hispanic, homeless and geriatric populations. Lack of dental and medical care to children other than required immunizations was also enlightening to many students. This was especially true for students who found these populations, "right in my backyard". One group of students cited lack of recreational facilities, lack of groomed playgrounds, overweight children, no sidewalks, many fast food restaurants, lack of access to fresh fruits and vegetables, and dangerous neighborhood surroundings. The students often come into the class with biases or perceptions about groups of people. These biases and fixed perceptions will often change when they interact with these populations. For example, finding out that homelessness is not a choice, but based on circumstances beyond the person's control. The students quickly learn to appreciate their own circumstances and are glad they were able to give back to their selected community. They realize that they are role models in the community in which they live and work.

\section{Conclusion}

Ultimately, the projects have been very successful, the class will continue to explore new service-learning projects that are of mutual benefit to the students, clients, College of Nursing and community. As Schwartz and Laughlin reported,

"This merger provided an opportunity to meet the School of Nursing's mission by providing service-learning opportunities for students and access to needed health promotion and prevention activities in the community" [14]

This activity was conducted to provide community health nursing students with an opportunity to assess a community of their choice as a "client" ${ }^{\text {[4] }}$. This service-learning experience allowed students to be active in a real world setting and to use their creative abilities to provide a needed service. The student's use of an evidence- based practice article and community resource agencies opened their eyes to other avenues and experiences to help members of their community. The group working together simulated collaborative working situations that commonly occur while working as a community health nurse. This experience allowed the students to use critical thinking and clinical skills as they developed their projects and interacted with community citizens. Further use of this service-learning project will continue to provide needed assistance in many community locations and provide valuable learning experiences for senior community health nursing students.

An evaluation from a student whose group provided help at a group home for the developmentally disabled included the following statement that sums up the effects of the service-learning efforts.

"This small place touched my heart on a really deep level. The student's all worked together well to come up with activities that would be appropriate for all of the residents. I wished that there was more I could do to help the residents that do not have the capabilities to participate in activities. Two of the students performed exercises with a relatively large group of patients, and the other two read books to the lower functioning patients. By the end of the day, the residents did not want us to leave. The atmosphere at this group home is very home like. The rooms were individualized for each patient and some of the patients were very enthusiastic about showing the students their rooms. The students participated equally in all parts of the community project. I would also like to say that this class has encouraged me to participate and organize more community projects. I feel that the group home could benefit from more visits from students at the University of South Alabama". (Student from USA College of Nursing) 
This student and the others in her group came back to class after the project was completed and were very excited to share with the class their experience. There are many more evaluations similar to this, which makes the instructors aware that the community health project is very worthwhile!

As previously stated, outcomes and evaluation of service-learning projects for this community health nursing course have been traditional in terms of grading through rubric (see Table 2,3), preceptor evaluation (see Table 4), instructor evaluation, group presentation, and peer evaluation. Anecdotal evaluation by the authors has been similar to that found by Schwartz and Laughlin,

"No schools have discontinued services since inception of the program and, based on recommendations from participating schools, additional schools have expressed a desire to participate."[14]

All facilities involved in this community health course (see Table 1) have requested students to return in following semesters to continue to provide services within their communities. Collaboration and partnership within the diverse communities has led to mutual benefits for all.

In summary, the next generation of nurses caring for individuals in the community is currently in the hands of community health nurse educators. It is our responsibility to take the economic and nursing shortage issues our country is currently facing into consideration when trying to solve problems for creative clinical experiences ${ }^{[15]}$. As we work to this end, we must encourage students of nursing to become agents of change while learning to collaborate and incorporating health promotion, illness prevention and primary health care to individuals residing in their chosen communities.

\section{References}

[1] Zungolo, E. Faculty preparation: Is Clinical Specialization a Benefit or a Deterrent to Quality Nursing Education? The Journal of Continuing Education in Nursing. 2004; 35: 19-23. PMid: 14870906

[2] Ganley,B.,Sheets, I. A Strategy to Address the Nursing Faculty Shortage. Journal of Nursing Education. 2009; $48(7)$ : $401-405$. http://dx.doi:10.3928/01484834-20090615-08

[3] Cashman, S., Hale, J., Candib,L., Nimoroski, T., Brookings, D. Applying Service-Learning through a Community-Academic Partnership: Depression Screening at a Federally Funded Community Health Center. Education for Health. 2004; 17(3): 313-322. PMid: 15848818

[4] Stanhope, M.,Lancaster, J. Foundations of Nursing in the Community. 3rd ed. St Louis, MO: MOSBY/Elsevier. 2010. IBSN 978-0-323-06655-6

[5] Groh, C., Stallwood, L., Daniels, J. Service-Learning in Nursing Education: It’s Impact on Leadership and Social Justice. Nursing Education Perspectives, November / December. 2011; 32 (6): 400-405. http://dx.doi.org/10.5480/1536-5026-32.6.400

[6] National Service-Learning Clearinghouse. 2012. Available from: www.servicelearning.org/topic/theory-practice/history-sl.

[7] Reising, D., Shea, R., Allen, P., Laux, M., Hensel, D., Watts, P. Using service-learning to develop health promotion and research skills in nursing students. International Journal of Nursing Education Scholarship. 2008; 5(1): 29. PMid: 18673297

[8] Erickson, G. P. Community health nursing in a nonclinical setting: Service learning outcomes of undergraduate students and clients. Nurse Educator. 2004; 29(2): 54-57. PMid: 15085004

[9] Hale, A. Service Learning within the Nursing Curriculum. Nursing Education.1997; 22(2): 15-18. ISSN: 0363-3624 Accession: 00006223-199703000-00011

[10] McKinney, D. Purnell, S. Service-learning Startup Kit for Higher Education. Center for Academic Service Learning and Civic Engagement. University of South Alabama. 2012

[11] Wade, G., Hayes, E. Challenges and opportunities associated with preceptored community health clinical experiences Public Health Nursing. 2010; 27(5): 459-467. http://dx.doi: 10.1111/j.1525-1446.2010.00879.x

[12] Callen, B., Block, D., Joyce, B., Lutz, J., Schott, N. B., Smith, C.M. Essentials of Baccalaureate Nursing Education for entry level Community/Public Health Nursing. Association of Community Health Nursing Educators (ACHNE). Wheat Ridge, CO. Fall 2009.

[13] Reifsnider, E. Dominguez, A., Friesenhahn, J, Hodges, P., Chapin, C., Sims, B. Collaboration with city agencies: A winning approach to community assessment. Journal of Nursing Education. 2005; 44(7): 323-325. PMid: 16094792 
[14] Schwartz, M. Laughlin, A. Partnering with Schools: A Win-Win Experience. Educational Innovations. $2008 ; 47$ (6): 279. http://dx. doi.org/10.3928/01484834-20080601-09

[15] Pijl-Zieber, E. M., Kalischuk, R. G. Community health nursing practice education: the next generation. International Journal of Nursing Education Scholarship. 2011; 8(1): 1-13. http://dx.doi.org/10.2202/1548-923X.2250 